\title{
Impact of oral care protocol on the incidence and severity of stomatitis induced by radiotherapy.
}

\author{
Amany M. Shebl . Amira A. Hassanein Wafaa I. Sherief \\ Faculty of Nursing-Mansoura University-Medical Surgical Nursing Department.
}

\begin{abstract}
:
Background: Oral stomatitis is a common debilitating complication of cancer radiotherapy. It results from local effects of radiation on the oral mucosa. The impact of oral stomatitis is far-reaching for patients, caregivers and the medical system. Objective: the aim of the study was to assess impact of oral care protocol to radiotherapy induced stomatitis in cancer patients. Methods: Quasi-experimental research design was conducted in the Clinical Oncology and Nuclear Medicine Department at Main Mansoura University Hospital. The data were collected from two hundred adult patients of both sex randomized selected who corresponded to inclusion criteria and divided into two groups. Results: the result indicates increased total knowledge score for patients at immediate post more than post tests 1 and post test 2. Also it was found decreased incidence and severity of stomatitis after oral care protocol. There were a positive relation between severity and incidence of stomatitis of studied patients in relation to their knowledge.

Conclusion: The implementation of oral care protocol had a positive effect on the studied patients' total knowledge scores and decrease incidence and severity of stomatitis in the study group. It was recommended that, Cancer patients should be given a written instruction plan for their radiotherapy steps and selfmanagement measures to radiotherapy.
\end{abstract}

Keywords: Cancer, Stomatitis, Radiotherapy

\section{Introduction}

Stomatitis is a common complication in patients receiving radiation for head and neck cancer, the risk increases with higher radiation doses, combined modality treatment; patient age, co morbidities and the condition of the oral mucosa. Stomatitis is characterized by inflammation and ulceration resulting from destruction of epithelial stem cells occurring in a multiphase process .It has a major impact on daily functioning, well-being, quality of life, cost of medical care, and treatment outcomes. Stomatitis typically occurs in the floor of the mouth, the buccal regions, the tongue, and the soft palate. It is clinically evident by the second week of radiation, peaks from weeks 5 to 6 , and can last for several weeks following treatment. ${ }^{1}$

Infections related to myelosupperssion and inflammation also can create localized super infections, damaging the mucosa and putting patients at risk for systemic infections. Mucosal inflammation may lead to sloughing of cells which causing the mucosa to become thin, denuded and ulcerated. When leukocytes are reduced in numbers or impaired in quality susceptibility to infection occurs. ${ }^{2}$ so damaged oral mucosa serves as an entry for micro organisms, these microorganisms can cause localized infections and have the potential to spread via blood stream and cause systemic sepsis and eventual death. ${ }^{3}$

Erythematous areas may develop into elevated white desquamative patches and subsequently into painful ulcers. Also clinical manifestations can progress from erythema, cracking lips, difficulty wearing dentures, ropy or absent saliva and inflammation to pain, bleeding, and ulceration or pseudomembraneous formation, which interfere with speaking, swallowing, eating, and xerostomia. ${ }^{4}$ Moreover, impaired nutrition and fluid intake, resulting in malnutrition and dehydration which further interfere with mucosal regeneration. The movable nonkeratinized mucosa of the soft palate, cheeks and lips, the ventral surface of the tongue, and the floor of the mouth are most vulnerable to direct stomatotoxicity. Interestingly, lesions tend to reappear without scar formation unless stomatitis is complicated by serious infection or xerostomia. Thus, patients with these problems can become withdrawn, socially avoidant, and even clinically depressed as a result of the difficulties and frustrations they encounter living with oral complications. ${ }^{5,6}$

A baseline assessment of the oral cavity of all cancer patients is necessary to identify problems that should be dealt with prior to treatment. ${ }^{1,8}$ Assess oral hygiene practices, personal attitudes, and knowledge of oral health and techniques of oral care as a basis for an individualized teaching plan and identify changes during the course of treatment. A systemic assessment should take place. ${ }^{4}$

Primary preventive measures, such as appropriate nutritional intake, effective oral hygiene practices, and early detection of oral lesions are important pretreatment interventions. ${ }^{9}$ A program of oral hygiene should be initiated with emphasis on maximizing patient compliance on a continuing basis. In order to maximize outcomes, the oncology team should clearly advise the dentist as to the patient's medical status and oncology 
treatment plan. In turn, the dental team should delineate and communicate a plan of care for oral disease management before, during, and following cancer therapy. ${ }^{10} \mathrm{~A}$ dentist should examine the patient 2-4 weeks prior to treatment to promote dental healing. ${ }^{11,12}$

The overall goal of the oncology nurse or the all health team is to complete a comprehensive oral care plan that eliminates oral disease. Achieving this goal will most likely reduce risk of oral toxicities with resultant reduced risk for systemic complication, reduced cost of patient care, and enhanced quality of life. If the patient is unable to receive the medically necessary oral care in the community, the oncology team should assume responsibility for oral management. ${ }^{13,14}$

Most none medicated oral care protocols utilize topical, frequent (every 4-6 hr) rinsing with $0.9 \%$ saline. Additional interventions include dental brushing with toothpaste, dental flossing, ice chips, and sodium bicarbonate rinses. Patient compliance with these agents can be maximized by comprehensive overseeing by the health care professional. ${ }^{15}$

Utilize a soft nylon bristled toothbrush 2 to 3 times a day maintain the gingival portion of the tooth and periodontal sulcus keeping them free of bacterial plaque. Rinsing the toothbrush in hot water every 15 to 30 seconds during brushing will soften the brush and reduce risk for trauma. ${ }^{16}$ oral rinsing with water or saline 3 to 4 times while brushing will further aid in removal of dental plaque dislodged by brushing. Rinses containing alcohol should be avoided. It can irritate oral soft tissues; toothpaste with relatively neutral taste should be considered. ${ }^{17}$ Flossing allows for interproximal removal of dental bacterial plaque and thus promotes gingival health. ${ }^{18}$

The oral cavity should be cleaned after meals. If xerostomia is present, frequent hygiene may be necessary. Dentures need to be cleaned via denture cleanser every day, and should be brushed and rinsed after meals, wear only when eating, and soak in antimicrobial solution when not being worn. ${ }^{19}$ the importance of prevention the dryness of the lips in order to reduce risk for tissue injury. Lip care products containing petroleum-based oils and waxes can be useful. ${ }^{20}$ Lanolin-based creams and ointments, however, may be more effective in protecting against trauma. ${ }^{21,22}$

Teaching patients smoking should be avoided. Seasoning or marinating food and experimentation with different foods are ways to deal with taste changes. Serving food at room temperature may blunt peculiar tastes. Small, frequent meals can help maintain adequate caloric intake. Increasing fluids to 2 to 3 liters per day can prevent dehydration. ${ }^{23}$ Tooth decay and caries may occur as late effect of radiation when the oral cavity is in the treatment field. In chronic xerostomia, saliva is unable to restore oral $\mathrm{pH}$ and regulate bacterial populations. This leads to an environment conducive to colonization of caries associated bacteria and enamel demineralization. Dental caries may set in 3 to 6 months after radiation is completed. ${ }^{22}$ If restorative work or extractions are necessary, this should be completed 10- 14 days before radiation begins to allow time for healing. ${ }^{20}$

\section{Aim of the study}

The study was conducted to assess the impact of oral care protocol on stomatitis for cancer patients undergoing radiotherapy.

Materials:

\section{Materials And Method}

\section{Research design}

Quasi-experimental research design was utilized in this study.

\section{Subjects:}

Sample of this study comprised two hundred adult patients of both sexes randomized selected. Who were diagnosed as having cancer and planned to receive radiotherapy

\section{Setting of the study}

The study was carried out in the inpatients ward and radiotherapy administration setting (out patients) of the Clinical Oncology and Nuclear Medicine Department at Main Mansoura University Hospital.

\section{The study subjects were consisted of two equal groups:}

The study subjects were divided randomly into two equal groups: Group (A): study group, consisted of one hundred adult patients were followed oral care protocol.

Group (B): Control group, consisted of one hundred adult patients were followed routine hospital care.

Tools of the study

Two tools were utilized by the researchers. As following: 
Impact of oral care protocol on the incidence and severity of stomatitis induced by radiotherapy.

Tool I: Structured Interviewing questionnaire.

It was developed by the researchers after reviewing the relevant literature. This tool included two parts:

\section{Part 1: Biosociodemographic data and medical data sheet.}

This part was developed by the researcher; it aimed to collect personal, social and medical patient data. Questions about patient's age, sex, level of education, occupation, marital status, duration of disease, data related to previous hospitalization, family history related to disease, diagnosis, grade of cancer, previous methods of treatment if present, type of radiotherapy used, schedule of sessions of radiotherapy planed to take, and problem (side effect) occur during radiotherapy e.g. stomatitis.

\section{Part 2: Patient's knowledge in related to stomatitis.}

It was used to examine the patient's knowledge in-relation to stomatitis, and self care measures to mange it. Then follow up the progress in the level of patient's knowledge through four assessment sheets (before, immediate post test, post test 1 , and post test2) to make comparison between them.

Toll II: WHO Oral Toxicity Scale (Otto, 2003).

This tool was developed by Otto (2003). This scale was adapted by the researchers to evaluate the incidence and severity of stomatitis in cancer patients received radiotherapy. This part was used in all phases of assessment in this study for the two groups (study and control groups). The WHO oral toxicity scale meets anatomical, symptomatic and functional components of stomatitis. Severity of oral stomatitis graded from (0) to (4). Listed as following grade (0) no side effects, (1) sore mouth no ulcers, (2) sore mouth with ulcers but able to eat normally, (3) able to eat liquids only and (4) unable to eat and drink.

\section{Method:}

- A permission to conduct the study was obtained from the Oncology and Nuclear Medicine Department administrator and head of department at Mansoura University Hospital.

- An informed written consent was taken from the study sample before inclusion in the study, after explanation the purpose of the study. The researcher emphasized that participation in the study was entirely voluntary and anonymity, each patient was informed that refusal to participate in the study wouldn't affect their care. At any time of the study the patient has the right to withdraw from the study.

- Pilot study: A pilot study was carried out on $10 \%$ of the subjects (20 patients) undergoing radiotherapy for testing feasibility and applicability of the tools. The needed corrections, modifications, omission and addition were made. Patients included in the pilot study were excluded from the study subjects.

- Subjects of control group followed a routine hospital care while subjects in study group followed the oral care protocol to radiotherapy side effects along with routine hospital care.

- Oral care protocol session was conducted for the study group patients before their starting in radiotherapy sessions.

- The data for the two groups (study and control) were collected throughout four phases of assessment and scheduled as following:-

- The first phase was done prior to conducting the oral care protocol.

- The second phase was done immediately post implementing oral care protocol, the third phase was don two third of radiotherapy sessions, and the fourth phase was done immediately after finishing the course of radiotherapy sessions.

- Implementation of oral care protocol, the implementation phase was done through five major sessions; each session was conducted for 5 to 10 patients sometimes for each patient individually according his condition, one session per day; the time allowed varies between 20-50 minutes.

- All sessions were ended before second phase of assessment. All Patients in the study group should perform oral care correctly at the end of sessions.

\section{Statistical analysis}

Data were collected, computed and statistically analyzed using Statistical Package for Social Sciences (SPSS) version16.0. For continuous variables (mean \pm SD) were used for comparison a $t$ test, paired $t$ test, and a series of a nova $t$ tests were used for detection of significances difference for independent groups, same group (pre\& post) and more than two groups respectively. For categorical variable comparison between group using chi-square test, the difference was considered significant at $\mathrm{P} \leq 0.05$. 


\section{Figure I}

\section{Results:}

Regarding to the age, figure revealed that, $52 \%$ of patients in the study group were in the age group of 50 years and over with mean age (46.92 \pm 8.64$)$. Forty nine percent of patients in the control group were in the same age group with a mean age $(45.53 \pm 10.84)$.

\section{Figure II}

Inrelation to sex, most of study subjects were females. They constituted $60 \%$ of the study and $58 \%$ of the control group. No significant difference was detected between the two groups $\left(x^{2}=\mathbf{0 . 0 8 3}, P=>\mathbf{0 . 0 5}\right)$.

\section{Figure III}

Concerning level of education there was no significant difference was detected $\left(\mathrm{x}^{2}=\mathbf{0 . 9 5 3}, \mathrm{P}=>\mathbf{0 . 0 5}\right)$. Secondary education was prevailing among $38 \%$ of the study group and $40 \%$ of the control group. Thirty percent of the study group and $24 \%$ of the control group were illiterate.

\section{Figure IV}

The health relevant data included medical diagnosis, date of disease discovery, grade of cancer, session's numbers of radiotherapy, site of radiotherapy, and previous treatment. The table reveals that, breast cancer and GIT cancer were the most prevailing among the study group (40\% and $28 \%)$ and $(28 \%$ and $38 \%)$ of the control group, with no statistical significant difference between the two groups $\left(\mathrm{x}^{2}=5.552, \mathrm{P}=>0.05\right)$ as regards medical diagnosis.

Table I:

The table revealed that, post implementing oral care protocol; patients in the study group had a highly statistically significant improvement in total knowledge score about radiotherapy $(54.84 \pm 7.81)$, with a highly statistical significant difference at before vs. immediate after test $\left(\mathrm{t}=28.018\right.$ at $\left.\mathrm{p} \leq 0.001^{* *}\right)$ and the gains were maintained throughout the period of after tests (after I 53.44 \pm 8.1 and after $252.1 \pm 8.88$ ). It could be mentioned that, the differences between the study and control groups at immediate after, after 1 and after 2 tests were statistically significant $\left(\mathrm{p} \leq 0.001^{* *}\right)$ respectively. Also the table revealed that, no statistically significant difference was found between the study and control groups as regards knowledge score about radiotherapy at pre test $(\mathrm{t}=3.76$ at $\mathrm{p}>0.05)$.

Table II:

The table clarifies that, there were significant differences between scores of the study group pre and post implementation of oral care protocol in relation to stomatitis radiotherapy side effects where $t=(86.176)$ at $\mathrm{p} \leq \mathbf{0 . 0 0 1} * *$

Regarding pre applying oral care protocol the table reveals that, the differences between scores of the study and control groups were not statistically significant $(p>0.05)$. on the other hand, differences between scores for stomatitis radiotherapy side effects of the study and control groups immediate after, after 1, and after 2 tests after applying nursing management protocol sessions were statistically significant where $(\mathrm{p} \leq \mathbf{0 . 0 0 1} * *)$.

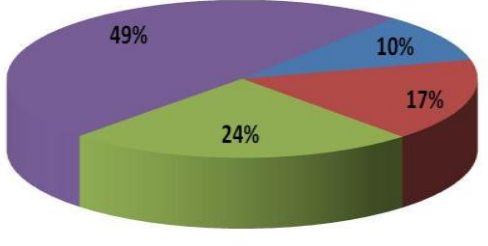

Control group

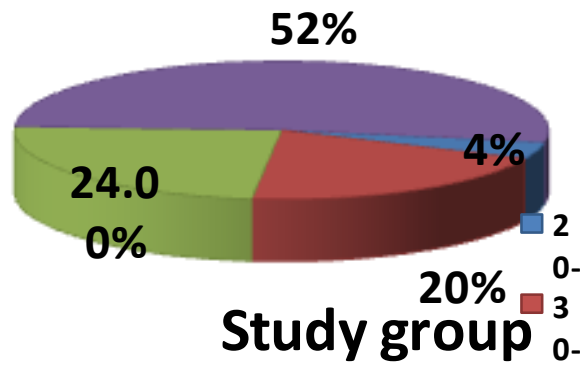

Figure (1): Distribution of the studied groups by age 




Figure (2): Distribution of the studied groups by gender

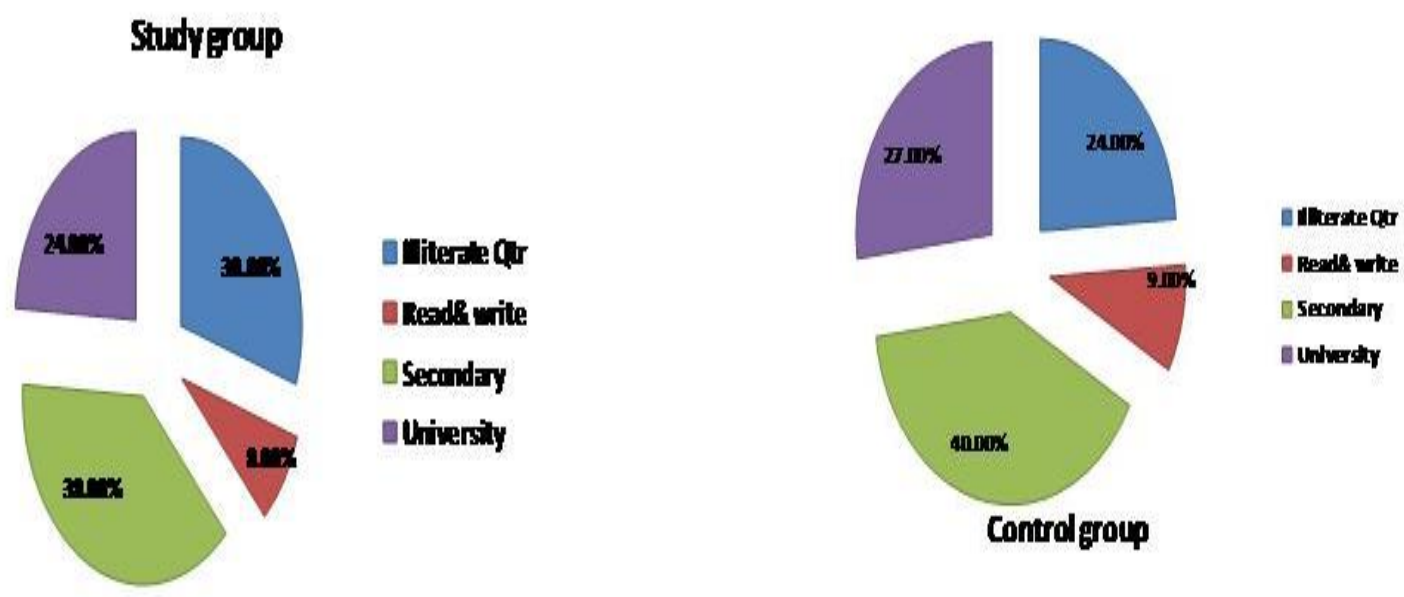

Figure (3): Distribution of the studied groups by level of education

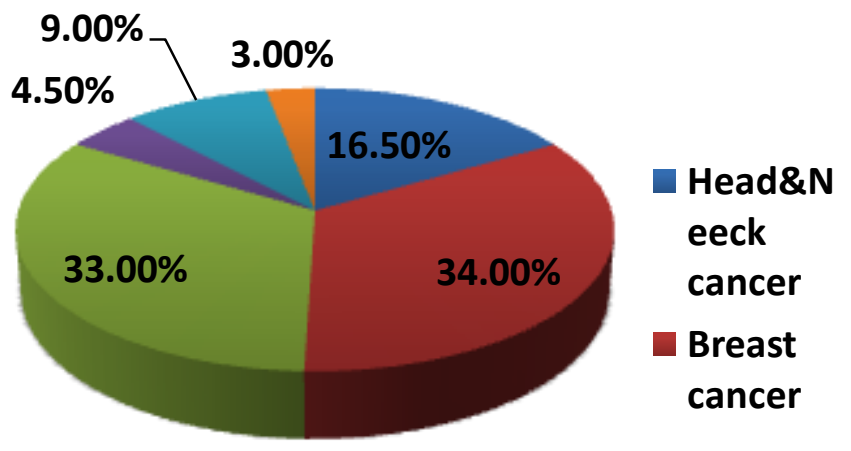

Figure (4): Distribution of the studied sample by medical diagnosis 
Impact of oral care protocol on the incidence and severity of stomatitis induced by radiotherapy.

Table I: Mean score, standard deviation and test of significance of patient's total knowledge score about radiotherapy of the study and control groups after nursing management protocol implementation.

\begin{tabular}{|c|c|c|c|c|c|c|}
\hline Item & & Study group & $\begin{array}{l}\text { Control } \\
\text { group }\end{array}$ & & & \\
\hline Kn & ledg & Mean \pm SD & Mean \pm SD & $\mathbf{t}$ & $\mathbf{X}^{2}$ & P-value \\
\hline Pretes & & $22.92 \pm 7.9$ & $18.3 \pm 9.02$ & 3.76 & 2.020 & $>0.05$ \\
\hline Post te & & $54.84 \pm 7.81$ & $24.15 \pm 8.86$ & 25.986 & 194.7 & $\leq 0.001^{* *}$ \\
\hline Pre vs. post & $\mathbf{t}$ & 28.018 & 4.321 & & & \\
\hline & p & $<0.001 * *$ & $<0.01$ & & & \\
\hline Follow u & & $53.44 \pm 8.1$ & $27.8 \pm 8.72$ & 21.479 & 180.3 & $\leq 0.001^{* *}$ \\
\hline Follow u & & $52.1 \pm 8.88$ & $30.27 \pm 9.47$ & 16.812 & 148.2 & $\leq 0.001^{* *}$ \\
\hline
\end{tabular}

Table II: Mean score, standard deviation and test of significance of patient's knowledge concerning dealing with stomatitis as radiotherapy side effects of the study and control groups after nursing management protocol implementation.

\begin{tabular}{|c|c|c|c|c|c|}
\hline \multirow{2}{*}{\multicolumn{2}{|c|}{$\begin{array}{l}\text { GIT radiotherapy side } \\
\text { effects }\end{array}$}} & \multicolumn{2}{|c|}{ GROUPS } & \multirow[b]{2}{*}{$\mathbf{t}$} & \multirow[b]{2}{*}{$\mathbf{P}$} \\
\hline & & $\begin{array}{c}\text { Study group } \\
\text { Mean } \pm \text { SD }\end{array}$ & $\begin{array}{c}\text { Control group Mean } \pm \\
\text { SD }\end{array}$ & & \\
\hline \multicolumn{6}{|c|}{ Stomatitis } \\
\hline \multicolumn{2}{|c|}{ Before implementation test } & $1.01 \pm 0.38$ & $0.92 \pm 0.37$ & 1.698 & $>0.05$ \\
\hline \multicolumn{2}{|l|}{ Immediate after } & $9.8 \pm 1.08$ & $1.64 \pm 0.99$ & 55.626 & $\leq 0.001^{* * \pi}$ \\
\hline \multirow[t]{2}{*}{ Before vs. after } & $\mathbf{t}$ & 86.176 & 6.601 & & \\
\hline & $\mathbf{p}$ & $\leq 0.001^{* *}$ & $\leq 0.01^{* *}$ & & \\
\hline \multicolumn{2}{|l|}{ After 1} & $9.42 \pm 1.30$ & $1.7 \pm 1.1$ & 44.468 & $\leq 0.001^{* * *}$ \\
\hline \multicolumn{2}{|l|}{ after 2} & $9.18 \pm 1.55$ & $1.8 \pm 1.2$ & 37.432 & $\leq 0.001^{* * *}$ \\
\hline
\end{tabular}

Table III: Impact of oral care on incidence of stomatitis as radiotherapy side effect of the study and control groups at pre, post, and follow up tests.

\begin{tabular}{|c|c|c|c|c|}
\hline $\begin{array}{c}\text { Oral toxicity } \\
\text { scale }\end{array}$ & $\begin{array}{c}\text { Pre test } \\
\mathbf{1}^{\text {st }} \text { assess }\end{array}$ & $\begin{array}{c}\text { Post test } \\
\mathbf{2}^{\text {nd }} \text { assess }\end{array}$ & $\begin{array}{c}\text { Follow up1 } \\
\mathbf{3}^{\text {rd }} \text { assess }\end{array}$ & $\begin{array}{c}\text { Follow up2 } \\
\mathbf{4}^{\text {th }} \text { assess }\end{array}$ \\
\hline $\begin{array}{c}\text { Study group } \\
\text { Mean } \pm \text { SD }\end{array}$ & $0.0 \pm 0.0$ & $0.0 \pm 0.0$ & $0.02 \pm 0.14$ & $0.10 \pm 0.36$ \\
\hline $\begin{array}{c}\text { Control group } \\
\text { Mean } \pm \text { SD }\end{array}$ & $0.0 \pm 0.0$ & $0.14 \pm 0.35$ & $0.23 \pm 0.58$ & $0.31 \pm 0.71$ \\
\hline \multicolumn{1}{|r|}{$\mathbf{t}$} & 4.015 & 3.499 & 2.645 \\
\hline & $\mathbf{p}$ & $\leq 0.001^{* *}$ & $\leq 0.001^{* *}$ & $\leq 0.001^{* *}$ \\
\hline
\end{tabular}


Impact of oral care protocol on the incidence and severity of stomatitis induced by radiotherapy.

Table IV: Relation between incidence and severity of stomatitis radiotherapy side effects according Oral toxicity scale and the patient's total knowledge score at pre, post, and follow up tests

\begin{tabular}{|c|c|c|c|c|c|c|}
\hline \multirow[t]{2}{*}{ Oral toxicity scale } & \multicolumn{2}{|c|}{ study } & \multicolumn{2}{|l|}{ control } & \multirow[t]{2}{*}{$\mathbf{t}$} & \multirow[t]{2}{*}{$\mathbf{p}$} \\
\hline & $\begin{array}{c}\text { Incidence } \\
\mathrm{N} \\
\end{array}$ & Mean \pm SD & $\begin{array}{c}\text { Incidence } \\
\mathbf{N}\end{array}$ & Mean \pm SD & & \\
\hline Nothing & 92 & $9.06 \pm 1.54$ & 83 & $1.35 \pm 0.74$ & 41.378 & $\leq 0.001 * *$ \\
\hline pain & 6 & $10.33 \pm 0.82$ & 3 & $6.0 \pm 0.24$ & 8.881 & $\leq 0.001^{* * *}$ \\
\hline Pain\& ulcer & 2 & $11.0 \pm 1.41$ & 14 & $3.29 \pm 0.62$ & 14.582 & $\leq 0.001 * *$ \\
\hline
\end{tabular}

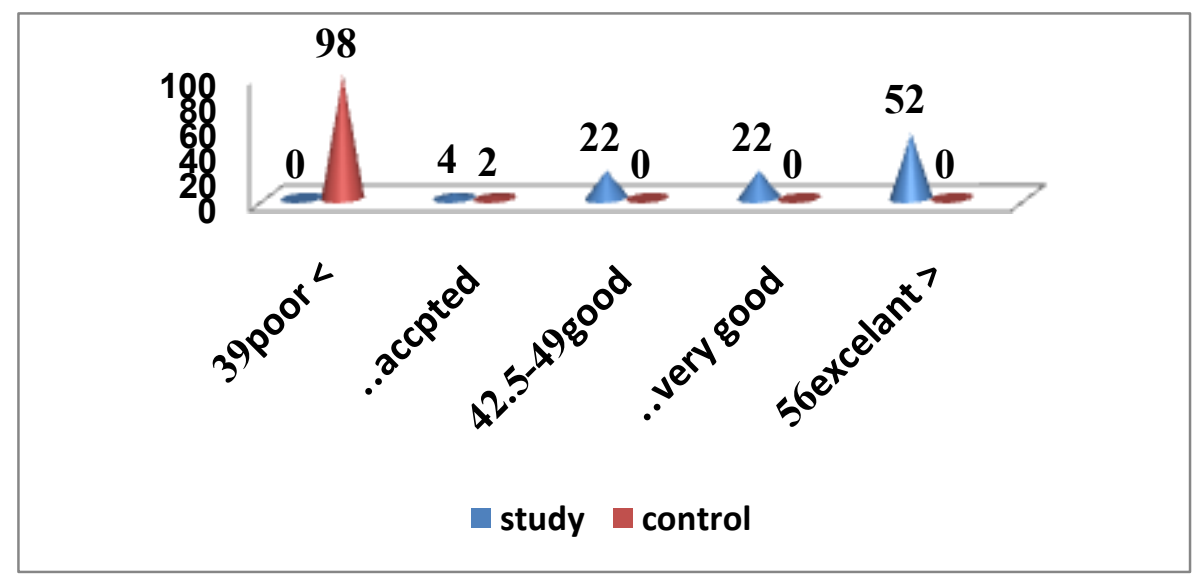

Figure 5: Total patient's knowledge score about radiotherapy of the study and control groups at immediate after test after nursing management protocol implementation.

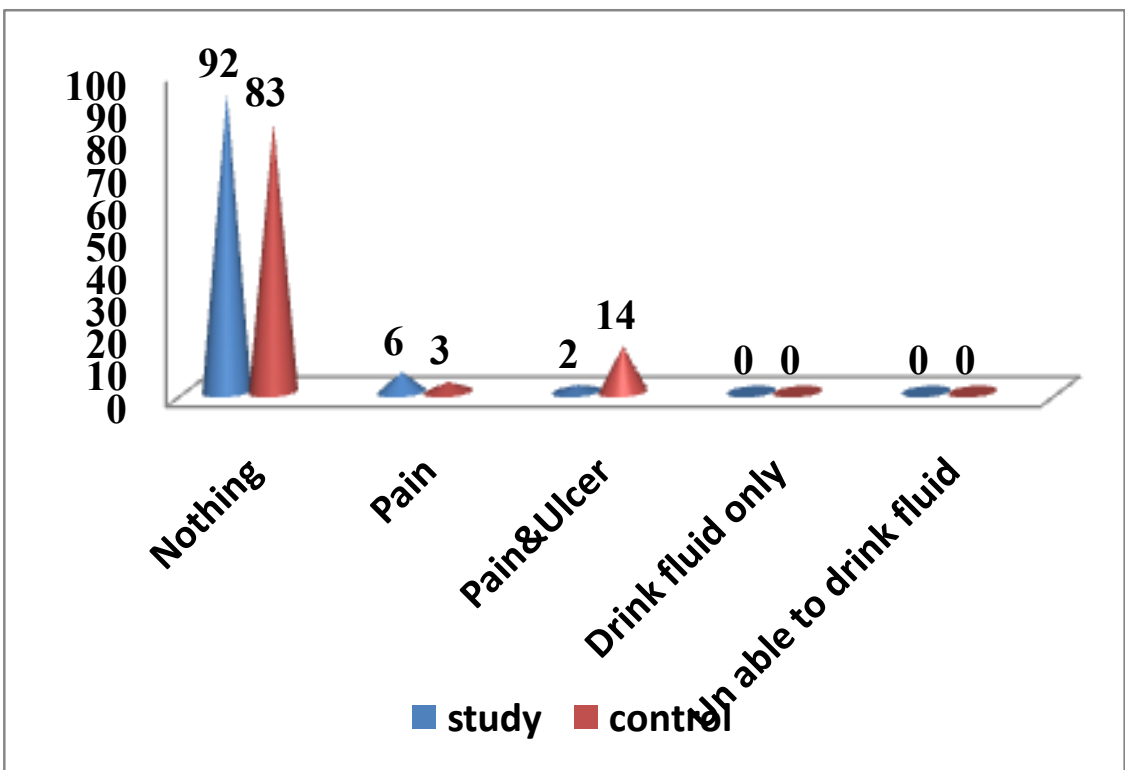

Figure 6: Severity of stomatitis as radiotherapy side effect of the study and control groups at the end of study (follow up2). 


\section{Table III:}

It appears from the table that, there were a significant difference between the study and control groups as regards incidence of stomatitis at immediate after, after 1 , and after 2 tests $\left(\mathrm{p} \leq 0.001^{* * *}\right)$. Furthermore, the results revealed increased in mean score of stomatitis for the patient in the control group at immediate after, after 1 , and after 2 tests $(0.14 \pm 0.35 \& 0.23 \pm 0.58 \& 0.31 \pm 0.71)$ respectively. On the other hand there were no statistical significant differences between study and control groups pre implementing oral care $(0.0 \pm 0.0)$.

\section{Table IV:}

Concerning to stomatitis, the table reveals that, there was significant decreased in incidence of stomatitis in the study group after nursing management protocol implementation than control group, statistically significant difference was found between the two groups $\left(\mathrm{p} \leq 0.001^{* *}\right)$. Six patients had pain in the study group while 14 patients had pain with ulcer in control group.

Figure 5: Shows total patient's knowledge score about radiotherapy of the study and control groups at post test after nursing management protocol implementation. It noticed that, 98 percent of the patients in the control group had poor knowledge score. On the other hand, there were $52 \%$ of patients had excellent score and twenty two percent very good knowledge score in the study group at post test.

Figure 6: Show severity of stomatitis as radiotherapy side effect of the study and control groups at the end of study (follow up2). It was found that, $92 \%$ of study group free from stomatitis compare to $19 \%$ suffering from stomatitis in the control group at follow up 2.

\section{Discussion:}

Incidence of breast cancer and gastrointestinal cancer were higher in the Egyptian population. ${ }^{23}$ This goes with the finding of the present study where more than one third of the

Subjects had breast cancer and about one third had GIT cancer. In the present study about three quadrate of the study subjects were discovered with incidence of disease time less than one year. This is in line with the Canadian Cancer Society which indicates that, with time there will be an increase in the rates of incidence of cancer for both males and females. ${ }^{24,25}$ Also this in harmony with report of (NCI) who found that, about 100,000 new cases of cancer discovered per year in Egypt. ${ }^{26}$

Oral stomatitis is a common debilitating complication of cancer radiotherapy. It results from local effects of radiation on the oral mucosa. The impact of oral stomatitis is far-reaching for patients, caregivers and the medical system. Oral stomatitis results in severe physical consequences for patients, impacting their quality of life and resulting in life-threatening complications. Ultimately, the development of oral stomatitis not only impacts long-term outcomes, but also leads to a significant financial and emotional burden for the patients and the medical system. ${ }^{27,28}$ regarding to the oral hygiene, the finding of the present study showed a highly significant statistical difference between the study group and the control group after following the oral care. So this finding confirms the statement that, mouth care reduces the incidence and severity of stomatitis.

This is goes in line with Wrthington who mentioned that poor oral hygiene make cancer patient at risk for stomatitis. ${ }^{29}$ This result was justified by Levi who stated that food debris and plaque accumulate in the oral cavity create good media to microorganism growth and changes in oral $\mathrm{PH}^{30}$ Therefore, frequent oral care make mouth fresh, free from food debris and prevent the dryness of the lips to reduce the risk for tissue injury of the oral cavity.

National Cancer Institute reported that, most people are able to maintain good oral hygiene independently throughout much of their lives. ${ }^{31}$ This is not agreeing with the present study, most of the subjects did not give an attention to oral care or oral hygiene. Patients give their attention to physical disease and do not go to dentist even with a problem in teeth. This may be due to decrease level of awareness about oral hygiene and its importance. Others, for reasons of physical or cognitive disability, or due to illness or advanced age, so these peoples will need assistance in carrying out dental and periodontal care to protect against gum disease, dental caries and risk for stomatitis.

In the present study, patients of control group appeared to be affected by stomatitis more than the study group who maintain the routine oral care. This is may be related to deposit of food, debris on teeth and left mouth at great risk for dryness, infection and bad mouth odor.

Concerning to relation of patients knowledge to severity of radiotherapy side effects the present study revealed that, decreased incidence and severity of stomatitis radiotherapy side effects for the study group at post, and follow up tests than control group. In agreement with this result Ashing-giwa confirm that, lower level of knowledge resulting in lack of awareness about cancer and available treatment, while knwolgeble patient are more aware about disease, side effects, and better access to care and its benefits. ${ }^{32}$ Also Padberg\& Padberg emphasized that, cancer patient with less knowledge need good assistance and more detailed explanation of their options to overcome disease stressed situation. ${ }^{33}$ On the other hand Johnson\& Blumberg stressed that, lack of 
Impact of oral care protocol on the incidence and severity of stomatitis induced by radiotherapy.

information may lead to increased severity of side effects, anxiety, and distress, also may impact negatively on the patient's satisfaction and may influence a patient's treatment choices and outcome. ${ }^{34,35}$

\section{V. conclusion:}

Based on the present study findings, it can be concluded that a marked gap in the knowledge of cancer patient receive radiotherapy. In addition, the results of the current study revealed that, both incidence and severity of stomatitis were significantly decreased in the study group after implementation of nursing management protocol.

Based on the results of the present study, the following recommendations are suggested:

- Cancer patients should be given a written instruction plan for their radiotherapy steps and self- management measures to radiotherapy.

- Oral protocol should be integrated within the plan of care for cancer patients going to radiotherapy. These protocol should be emphasize patients education about the disease process, treatment modalities, behavior and life style modification, different relaxation techniques, psychological support, financial support, and coping behaviors that the patients can integrate into their lifestyle.

- Development of cancer education center in nuclear- medicine department is essential to provide inpatient and outpatients oral care protocol for cancer patient receive different type of treatment modalities.

- Developed illustrated booklet should be available and distributed for each cancer patient admitted to the hospital.

- Further research is needed to document the positive effect of self care on the prevention of radiotherapy induced stomatitis.

[1]. Shih A, Miaslowski C, Dodd M, et al. Continuing education: A research review of the current treatment for radiation-induced oral mucositis in patients with head and neck cancer. Oncol Nurs Forum.2010; 29(7):1063-1080. http://www.who.int/uv/faq/skincancer/en/index1.html

[2]. Sonis ST. Oral mucositis in cancer therapy. I Supporl Oncol.2008; 16(13):3-8.

[3]. Dodd MJ. The pathogenesis and characterization of oral mucositis associated with cancer therapy. Oncol Nurs Forum.2011; 31(4):5-11.

[4]. Eilers J. Nursing intervention and supportive care for prevention and treatment of oral mucositis associated with cancer treatment. Oncol Nurs Forum.2009; 31(4): 13-23, 37-39.

[5]. Brizel DM. Wasserman TH, Henke M, et al. Phase III randomized trial of amifostine as a radioprotector in head and neck cancer. J Clin Oncol.2010; 18(19): 3339-3345.

[6]. Galvin JM, Ezzell G, and Eisbrauch A. "Implementing IMRT in clinical practice: a joint document of the American Society for Therapeutic Radiology and Oncology and the American Association of Physicists in Medicine". Int J Radiat Oncol Biol Phys. 2009; 58 (5): 1616-34

[7]. Sherry VW. Taste alteration among patients with cancer. Clin J Oncol Nurs.2009; 6(2):73-77,105-106.

[8]. American Cancer Society. Radiotherapy and stomatitis http://www.cancer.org/docroot/SPC/content/SPC_1_Minority_Cancer_Unequal_Burden.asp on 7/29/09. Accessed April 2010

[9]. Bellm LA, Cunningham G, and Durnell L. Defining clinically meaningful outcomes in the evaluation of new treatments for oral mucositis: oral mucositis patient provider advisory board. Cancer Invest.2010; 20(5/6): 793-800

[10]. Leung WK, Jin LJ, Yam WC, and Samaranayake LP. Oral colonization of aerobic and facultatively anaerobic gram-negative rods and cocci in irradiated, dentate, xerostomic individuals. Oral Microbial Immunol. 2011; 16: 1-9

[11]. Leglie PF, Mura G, and Mura A. Prevention of periodontopathy and oral mucositis during antineoplastic chemotherapy Clinical study. Minerva Stomatol.2011; 51(6): 231-39.

[12]. Avritscher Eb, Cookley CD, and Elting LS. Scope and epidemiology of cancer therapy induced oral and gastrointestinal mucositis. Seminar in Oncology Nursing. 2009; 20: 3-10.

[13]. Spijkervet F and Sonis S. New frontiers in the management of chemotherapy-induced mucositis. Curr Opin Oncol. $2008 ; 10$ (1): 523-527.

[14]. Nakamura K, Natsugoe K, and Kumanohoso T. Prophylactic action of allopurinol against chemotherapy-induced stomatitisinhibition of superoxide dismutase and proteases. Anticancer Drugs 2010; 7: 235-239.

[15]. Awidi A, Homsi U, and Kakail RI. Double-blind, placebo-controlled cross-over study of oral pilocarpine for the prevention of chemotherapy-induced oral mucositis in adult patients with cancer. Eur J Cancer. 2011; 37(16): 2010-2014.

[16]. Malik IA, Moid I, and Haq S. A double-blind, placebo-controlled, randomized trial to evaluate the role of tetrachlorodecaoxide in the management of chemotherapy-induced oral mucositis. J Pain Symptom Manage. 2010; 14(2): 82-87.

[17]. Sonis T, Eilers JP, and Epstein JB. Validation of a new scoring system for the assessment of clinical trial research of oral mucositis induced by radiation or chemotherapy. Cancer.2009; 85: 2103-2113

[18]. Cowen D, Tardieu C, and Schubert M. Low energy helium-neon laser in the prevention of oral mucositis in patients undergoing bone marrow transplant: results of a double blind randomized trial. Int J Radiat Oncol Biol Phys. 2010; 38(4): 697-703.

[19]. Ripamonti C, Zecca, Brunneli C, et al. A randomized controlled clinical trial to evaluate the effects of zinc sulfate on cancer patients with taste alterations caused by head and neck irradiation. Cancer. 2008; 82(10):3-10.

[20]. Edward B, Douglas E, and Linda S. Clinical practice guidelines for the prevention and treatment of cancer therapy- induced oral and gastrointestinal mucositis. Cancer Supplement. 2004; 100(9): 2026- 45. Available from: http://www.interscience.wiley.com

[21]. Rezvani M and Ross GA. Modification of radiation- induced acute oral mucositis in the rat. Int Radiat Biol.20004; 80:177-182.

[22]. Cheng KK, Molassiotis A, Chang AM, and Wai WC. Evaluation of an oral care protocol intervention in the prevention of chemotherapy- induced oral mucositis in cancer patients. Eur journal Cancer.2009; 37: 2056-63.

[23]. American Cancer Society. Cancer facts \& figures for Hispanics/Latinos 2009-2011. Atlanta.

[24]. Johnson, George. "Unearthing Prehistoric Tumors, and Debate". The New York Times.2010; 61:233-246. 
Impact of oral care protocol on the incidence and severity of stomatitis induced by radiotherapy.

[25]. Otto S. Oncology nursing. $5^{\text {th }}$ ed. London: Mosby; 2004: 300-315.

[26]. National Cancer Institution Egypt. Cancer facts and statistical.2010

[27]. Balducci L. National Comprehensive Cancer Network (NCCN) practice guidelines in oncology: senior adult oncology. (http://www.nccn.org/professionals/physician- gla/PDF/senior.) Accessed April 2010

[28]. Nakamura K, Natsugoe K, and Kumanohoso T. Prophylactic action of allopurinol against chemotherapy-induced stomatitisinhibition of superoxide dismutase and proteases. Anticancer Drugs. 2010; 7: 235-239.

[29]. Wrthington HV. Interventions for treating oral mucositis for patients with cancer receiving treatment. Cochrane Database Syst Rev. 2010; $1: 23$.

www.learningplaceonline.com/illness/cancer/mouth/problems.htm

[30]. Levi F, Zidani R, and Missel JL. Randomized multicentre trial of chronotherapy with oxaliplatin, fluorouracil, and folinic acid in metastatic colorectal cancer. Lancet. 2007; 350: 681-6.

[31]. National Cancer Institute. Common terminology criteria for adverse advents (v. 3.0). Bethesda, Md.2011. http://www.cancere.gov/cancerinfo/pdq/supportivecare/oralcomplications/healthprofessional

[32]. Ashing-Giwa KT, Padilla GV, Bohorquez DE, Tejero JS, and Garcia M. Understanding the breast cancer experience of Latina women. Journal of Psychosocial Oncology.2006; 24: 19-52.

[33]. Padberg RM and Padberg LF. Patient education and support: In cancer nursing principles and practice. $5^{\text {th }}$ ed. Boston: Jones and Bartlett.2009; p: 1609-1631.

[34]. Johnson JL and Blumberg BD. A commentary on cancer patient education. Health Educ Q. Spring.2008; 10 (1): 7-18.

[35]. National Cancer Institute: Oral complications of chemotherapy and head/neck radiotherapy. http://www.cancere.gov/cancerinfo/pdq/supportivecare/oralcomplications/healthprofessional. $\quad$ Accessed 2010 